\title{
A Study on Electric Drive of Vehicles
}

\author{
Kesarkar Manoj R \\ PG Student, Mechanical Engineering Department,Bhivarabai Sawant Institute of Technology \& Research Pune - 412207 (India)
}

\begin{abstract}
A Set of devices to convert electric energy into mechanical energy and to regulate the converted energy flus according to a specific law. It is most common type drive .Electric drives may be classified to design characteristics into three types: Single Motor Group and Multi motor. Single Motor electric drives and used for power tools, Simple metal working and Wood working machine tools and Household Appliances. Group electric drives are almost never used in modern Industry. Multi motor electric drives used in multi operation metal working machine tools as individual electric traction drives for rail road transportation equipment. Electric drives may also be divided into reversible and non - reversible types and depending on possibility of controlling the flux of the converted mechanical energy, into uncontrolled and controlled velocity types. Interest in electric drive vehicle technologies is growing, and their development accelerating, in the Automotive industry. This growth represents a shift of focus from market entry and environmental drivers to mainstream, customer committed development. A number of different power train archirectures have been considered and introduced in the market for different applications. This architectures are usually classified into five categories: Series, Parallel, Power Spilt, Voltec and Plug - in
\end{abstract}

Keywords: Power Train Configuration, Electric machine, Decision Tree

\section{Introduction}

Interest in electric drive vehicle technologies is growing, and their development accelerating, in the Automotive industry. This growth represents a shift of focus from market entry and environmental drivers to mainstream, customer committed development.

HVs combine at least two energy sources, such as an internal combustion engine (ICE), fuel cell system... with an energy storage system. Electric drive vehicles have the potential to reduce fuel consumption in several ways, including the following:

- Regenerative braking: A regenerative brake is an energy mechanism that reduces the vehicle's speed by converting some of its kinetic energy into a storable form of energy for future use instead of dissipating it as heat, as with a conventional friction brake. Regenerative braking can also reduce brake wear and the resulting fine particulate dust.

- Engine shutoff under various driving conditions (e.g., vehicle stopped, low power demand).

- Engine downsizing, which may be possible to accommodate an average load (not a peak load),would reduce the engine and power train weight. Higher torque at low speed from the electric machine also allows the vehicle to achieve the same performance as conventional vehicles with a lower vehicle specific power $(\mathrm{W} / \mathrm{kg})$.

- Optimal component operating conditions: For example, the engine can be operated close to its best efficiency line.

- Accessory electrification allows parasitic loads to run on as-needed basis.

- The energy storage systems of PHEVs and battery electric vehicles (BEVs) can also be recharged, further improving fuel displacement. However, vehicle electrification also have disadvantages that could affect fuel consumption, including increased vehicle weight due to additional components. Two major types of hybrids have been considered for transportation applications: electrical and hydraulic.

\section{Electric Drive Powertrain Configurations}

The various HEV power train configurations can be classified on the basis of their hybridization degree, as shown in Figure 1. The hybridization degree is defined as the percentage of total power that can be delivered electrically. The higher the hybridization degree, the greater is the ability to propel the vehicle using electrical energy.

A number of different power train architectures have been considered and introduced in the market for different applications. These architectures are usually classified into three categories: series, parallel, and power split. The following sections describe some of the possible power train configurations for each architecture.

\subsection{Series Electic Drive Hybrid Vehicle}

The first hybrids were generally based on a series configuration. As shown in Figure, series hybrid vehicles are propelled solely by electrical energy. When the engine is used, it provides a generator with mechanical power, which is then converted into electricity. In the case of a fuel-cell system, the electrical energy is directly used by the electric machine. The main advantage is that the engine speed is decoupled from the vehicle speed, allowing operating conditions at or close to the engine's most efficient operating point. The main drawback is that the main components have to be oversized to be able to maintain a uniform performance, leading to higher vehicle weight. Finally, the large number of components and the energy conversion from chemical to mechanical to electrical leads to lower power train efficiency. 


\section{International Journal of Science and Research (IJSR) \\ ISSN (Online): 2319-7064}

Index Copernicus Value (2015): 78.96 | Impact Factor (2015): 6.391

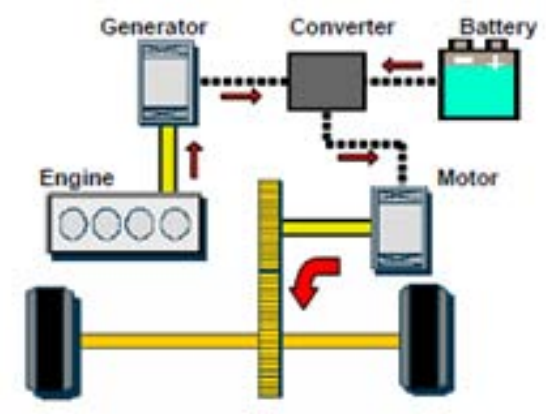

Figure1: Series Electic Drive

\subsection{Parallel Drive Hybrid Vehicle}

In a parallel configuration, the vehicle can be directly propelled by either electrical or mechanical power. Direct connection between the power sources and the wheels leads to lower power train losses compared to the pure series configuration. However, since all of the components' speeds are linked to the vehicle's speed, the engine cannot routinely be operated close to its best efficiency curve.

Several subcategories exist within the parallel configuration:

- MHEV: A small electric machine is used to turn the engine off when the vehicle is stopped. Examples include the Citroen C3.

- Starter-alternator: This configuration is based on a small electric machine (usually 5 to $15 \mathrm{~kW}$ )located between the engine and the transmission. Because of the low electricmachine power, this configuration is mostly focused on reducing consumption by eliminating idling. Examples include the Buick E-Assist (belt integrated), Honda Civic (crankshaft integrated), and Honda Accord (Crankshaft integrated).

- Pre-transmission: This configuration has an electric machine in between the engine and the transmission. The electric machine power ranges from 20 to $50 \mathrm{~kW}$ for light duty applications, which allows the driver to propel the vehicle in electric-only mode as well as recover energy through regenerative braking. . Examples of pretransmission HEVs currently in production include the Hyundai Sonata Hybrid and the Infiniti M35 Hybrid.
- Post-transmission: This configuration shares most of the same capabilities as the pretransmission. The main difference is the location of the electric machine, which in this case is after the transmission.

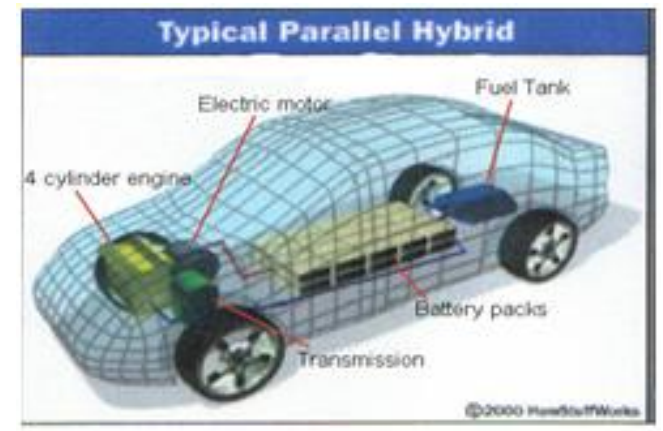

Figure 2: Parallel drive

\subsection{Power Split Drive Hybrid Vehicle}

As shown in Figure power split hybrids combine the best aspects of both series and parallel hybrids to create an extremely efficient system. The most common configuration, called an input split, is composed of a power split device (planetary gear transmission), two electric machines and an engine. Within this architecture, all these elements can operate differently. The operational phases for an input split configuration are the following:

- During vehicle launch, when driving, or when the state of charge (SOC) of the battery is high enough, the ICE is not as efficient as electric drive, so the ICE is turned off and the electric machine alone propels the vehicle.

- During normal operation, the ICE output power is split, with part going to drive the vehicle and part used to generate electricity. The electricity goes either to the electric machine, which assists in propelling the vehicle, or to charge the energy storage system. The generator also acts as a starter for the engine.

- During full-throttle acceleration, the ICE and electric machine both power the vehicle, with the energy storage device (e.g., battery) providing extra energy.

- During deceleration or braking, the electric machine acts as a generator, transforming the kinetic energy of the wheels into electricity to charge the energy storage system.
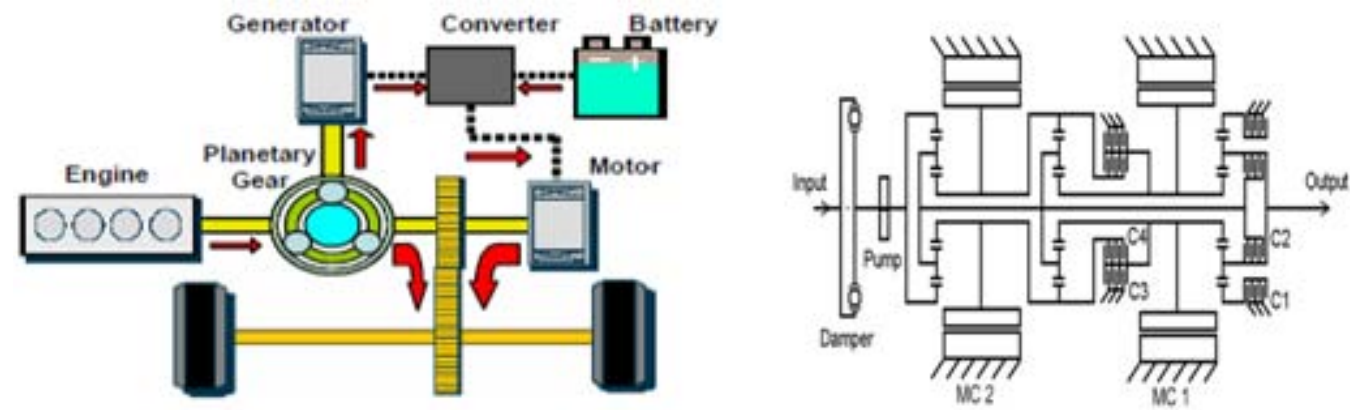

Figure 3: Power Split Drive

\subsection{Voltec Hybrid Vehicle}

In the past couple of years, configurations allowing different operating modes (e.g., series and parallel, parallel and power split) have been introduced in the market. The VOLTEC configuration from General Motors is an example of these configurations. The VOLTEC powertrain architecture, also called the EREV (Extended Range Electric Vehicle), provides four modes of operating, including two that are unique and maximize the power train efficiency and 


\section{International Journal of Science and Research (IJSR) \\ ISSN (Online): 2319-7064}

Index Copernicus Value (2015): 78.96 | Impact Factor (2015): 6.391

performance. The electric transaxle has been specially designed to enable patented operating modes, both to improve the vehicle's electric driving range when operating as a $\mathrm{BEV}$ and to reduce fuel consumption when extending the range by operating with an ICE.

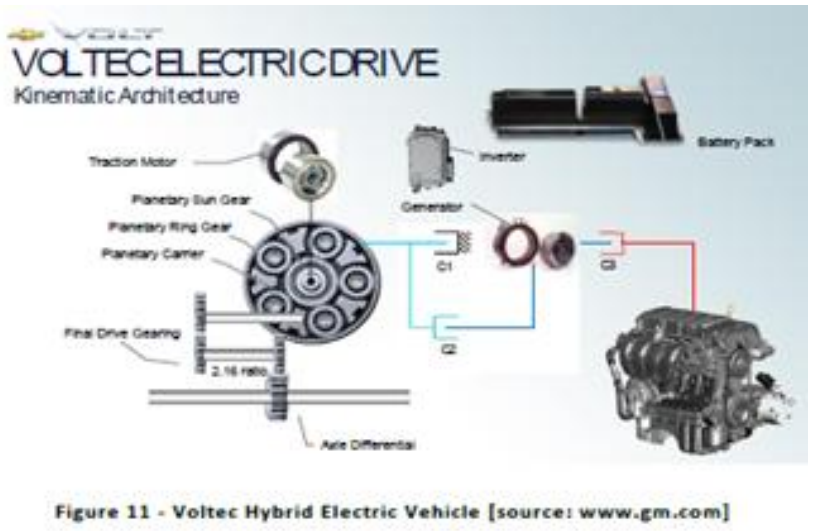

Figure 4: Voltec Electric drive

\subsection{Plug-In Hybrid Electric Vehicle}

PHEVs differ from HEVs in their ability to recharge the energy storage system through the electric grid. PHEVs energy storage systems have usually a higher total energy compared to HEVs and they also use a larger portion of it (e.g., when most HEVs use 10 to $15 \%$ of their total battery energy, PHEVs use from (60 to $70 \%)$. Since the vehicle is designed to have a high capacity energy storage, electrochemical batteries are usually used for this application. All the HEV configurations described above can be used as PHEVs.

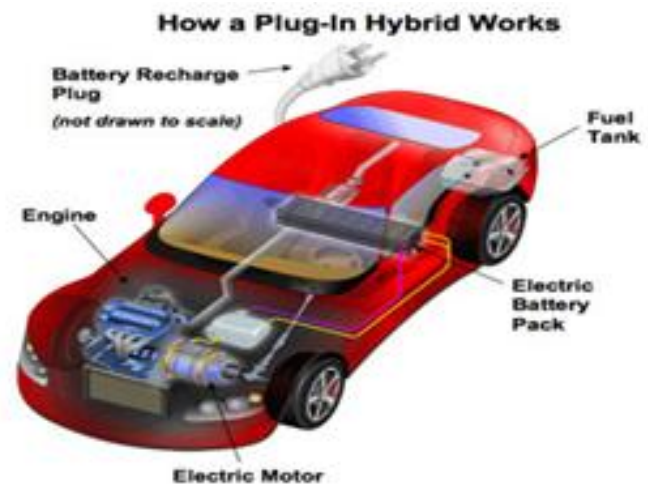

Figure 5: Plug-in Electric Drive Vehicle

\section{Model Assumptions}

The main objective of vehicle electrification is to provide drivers with better fuel consumption while maintaining or exceeding the performance and drive quality of conventional vehicles. The selection of hybridization degree and power train configuration is complex, since numerous options exist. On the basis of current production vehicles as well as future trends, the following powertrain configurations were selected for the modeling analysis to match NHTSA requests:

- 12-V MHEV

- BISG

- CISG
- Full HEV: single-mode power split configuration with fixed ratio for compact and midsize cars and two-mode power split with four fixed gears for small-SUV, midsizeSUV and pickup classes.

- PHEV20: single-mode power split configuration with fixed ratio (for compact, midsize and small-SUV classes) and two-mode (for midsize SUV and pickup classes) with 20-mile AER on the FTP (standard urban) drive cycle.

- PHEV40: Voltec configuration with 40-mile AER on the FTP drive cycle

- Fuel-cell HEV: series configuration with 320 miles range on the FTP drive cycle

- BEV with 100-mile AER on the FTP drive cycle

\subsection{Component Assumptions}

Five different vehicle classes were simulated in this study: compact car, midsize car, small SUV, midsize SUV, and pickup truck. The reference vehicles used as a starting point are based on conventional powertrains with the specifications summarized below and in Table

- Transmission: 5-speed gearbox with ratios of $[0,2.563$, $1.552,1.022,0.727,0.52]$

- Final drive ratio: 4.43

Table 1: Baseline Vehicle Main Specifications

\begin{tabular}{|c|c|c|c|c|c|}
\hline $\begin{array}{c}\text { Baseline Vehicle } \\
\text { Specification }\end{array}$ & Compact & Midsize & $\begin{array}{c}\text { Small } \\
\text { SUV }\end{array}$ & $\begin{array}{c}\text { Midsize } \\
\text { SUV }\end{array}$ & Pickup \\
\hline $\begin{array}{c}\text { Engine power } \\
\{\mathrm{KW}\}\end{array}$ & 121 & 130 & 148 & 178 & 203 \\
\hline $\begin{array}{c}\text { Vehicle test } \\
\text { Weight }\{\mathrm{Kg}\}\end{array}$ & 1370 & 1580 & 1606 & 1904 & 2172 \\
\hline Drag Coefficient & 0.3 & 0.3 & 0.4 & 0.41 & 0.45 \\
\hline Frontal Area $\left\{\mathrm{m}^{2}\right\}$ & 2.193 & 2.244 & 2.5704 & 2.9376 & 3.2742 \\
\hline $\begin{array}{c}\text { Rolling } \\
\text { Resistance } \\
\text { Coefficient } 1\end{array}$ & 0.0075 & 0.0084 & 0.0084 & 0.0084 & 0.009 \\
\hline $\begin{array}{c}\text { Rolling } \\
\text { Resistance } \\
\text { Coefficient } \\
\text { Speed term }\}\end{array}$ & 0.00012 & 0.00012 & 0.00012 & 0.00012 & 0.00012 \\
\hline
\end{tabular}

For each vehicle class considered in this study, all the vehicles have been sized to meet the same requirements:

- Initial vehicle movement (IVM) to $60 \mathrm{mph}$ in $9 \mathrm{sec}+/-0.1$ sec

- Maximum grade (grade ability) of $6 \%$ at $65 \mathrm{mph}$ at gross vehicle weight (GVW)

- Maximum vehicle speed $>100 \mathrm{mph}$

\subsubsection{Engine}

The engine is one of the main components affecting the fuel consumption performance of conventional and electric drive vehicles. The engine assumptions selected for this analysis represent state-of-the-art engine technologies. A portinjected engine with a peak efficiency of $35 \%$ was used for the conventional, MHEV and starter-alternator configurations (detailed map non available due to proprietary information). An Atkinson engine (Figure) was used for the other applications. 


\section{International Journal of Science and Research (IJSR) \\ ISSN (Online): 2319-7064}

Index Copernicus Value (2015): 78.96 | Impact Factor (2015): 6.391

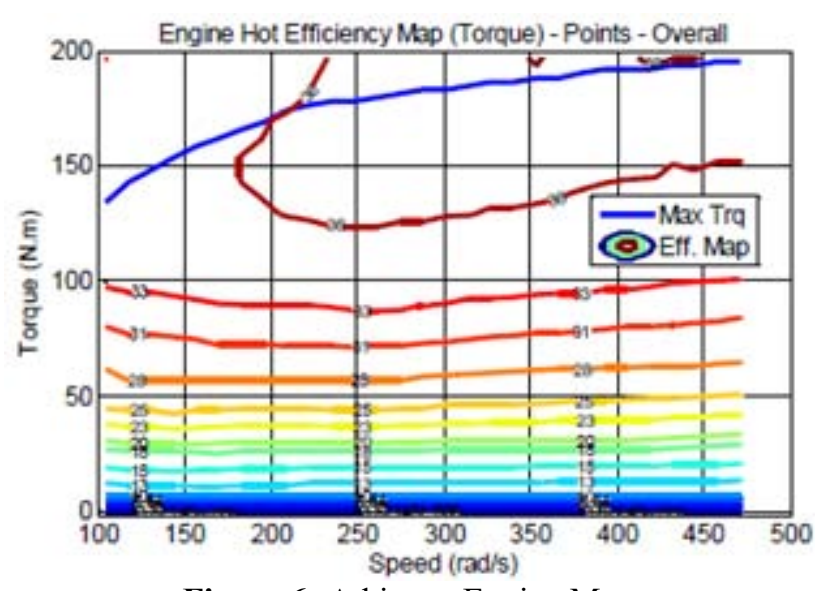

Figure 6: Atkinson Engine Map

\subsubsection{Electric Machine}

The electric machine performance data (Figure) were provided by Oak Ridge National Laboratory and represent a synchronous permanent-magnet technology. Figure represents the electric machine efficiency map use for the micro HEV, BISG and CISG. Figure represents the efficiency map of the electric machine used for the HEV and PHEVs. In both cases, the electric machine power was adjusted by scaling the torque values. The efficiency maps have been developed assuming component normal temperature operating conditions.

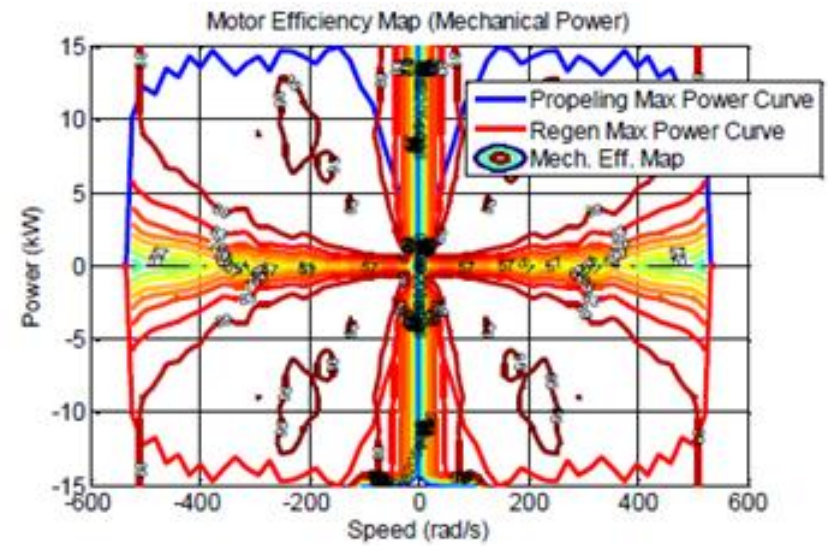

Figure 7: Electric Machine Map for Mirco and Mild HEV

These figures represent the peak torque curves. A constant ratio was assumed between the continuous and peak torque curves:

- 2 for the Micro, Mild HEVs

- 2 for the Motor 1 and 1.5 for the Motor 2 of the power split HEV and Blended PHEV

- 1 for E-REV, BEVs and Fuel cell HEV

However, due to the drive cycles considered, the electric machines were never limited. Finally, the electric machine specific weight is $1600 \mathrm{~W} / \mathrm{kg}$ and its controller $13000 \mathrm{~W} / \mathrm{kg}$.

\subsubsection{Fuel-Cell System}

The fuel-cell system was modeled to represent the hydrogen consumption as a function of the produced power. The fuel cell system peak efficiency, including the balance of plant, is $55 \%$ and represents normal temperature operating conditions. The data set cannot be provided as it is proprietary. The fuel cell system specific power is 305 $\mathrm{W} / \mathrm{kg}$. The hydrogen storage technology considered is high pressure tank with a specific weight of $0.028 \mathrm{kgH} 2 / \mathrm{kg}$. As mentioned previously, the tank was sized to provide 320 miles range on the FTP drive cycle.

\subsubsection{Transmission}

The conventional vehicle, the micro hybrid, as well as both mild hybrid (BISG and CISG) use the exact same transmission technology: 5-speed automatic transmission, with the following ratios:

- Gear1: 2.56

- Gear2: 1.55

- Gear3: 1.02

- Gear4: 0.72

- Gear5: 0.52

These transmission ratios were selected as they represent typical values for high volume vehicles currently on the market. Power-split HEVs and PHEV 20 AER both have a planetary gear set with 78 ring teeth and 30 sun teeth, similar to the Toyota Prius. The PHEV 40 AER has a planetary gear set with 83 ring teeth and 37 sun teeth, similar to the GM Voltec. The final drive ratios used:

- Conventional, micro and mild hybrid (BISG and CISG): 4.43

- Split HEVs and PHEV 20: 4.059

- PHEV 40: 4.44

The transmission shifting logic has a significant impact on vehicle fuel economy and should be carefully designed to maximize the powertrain efficiency while maintaining acceptable drive quality.

\subsubsection{Energy Storage System}

The battery used for the BISG and CISG HEVs as well as the PHEVs is a lithium-ion battery, as it is assumed that this is the most likely technology to be used. Table 2 provides a summary of the battery characteristics and technologies used by each powertrain.

Table 2: Energy Storage System

\begin{tabular}{|c|c|c|}
\hline & Technology & Reference Cell Capacity (AH) \\
\hline MHEV & Lead Acid & 66 \\
\hline BISG & Li-ion & 6 \\
\hline CISG & Li-ion & 6 \\
\hline HEV & Li-ion & 6 \\
\hline PHEVs & Li-ion & 41 \\
\hline
\end{tabular}

The battery capacity was selected for each option to allow a global pack voltage between $200 \mathrm{~V}$ (i.e., full HEV case) and $350 \mathrm{~V}$ (i.e., BEV case). The energy storage cell weights for the PHEVs are based on $220 \mathrm{Wh} / \mathrm{kg}$ for PHEVs and 290 $\mathrm{Wh} / \mathrm{kg}$ for the BEVs.

Different useable SOC ranges have also been selected depending on the powertrain configuration

- 20\% SOC range for micro, mild and full HEVs

- 70\% SOC range for PHEVs and BEVs

Vehicle test data have shown that, for the drive cycles and test conditions considered, battery cooling does not draw a significant amount of energy if anything at all for most of the vehicle powertrain architectures to the exception of

\section{Volume 6 Issue 1, January 2017




\section{International Journal of Science and Research (IJSR) \\ ISSN (Online): 2319-7064 \\ Index Copernicus Value (2015): 78.96 | Impact Factor (2015): 6.391}

BEVs. In that case, an additional constant power draw of $230 \mathrm{~W}$ was used to take into account battery cooling.

The energy storage system (ESS) block models the battery pack as a charge reservoir and an equivalent circuit. The equivalent circuit accounts for the circuit parameters of the battery pack as if it were a perfect open-circuit voltage source in series with an internal resistance. The amount of charge that the ESS can hold is taken as constant, and the battery is subject to a minimum voltage limit. The amount of charge required to replenish the battery after discharge is affected by coulombic efficiency.

\subsubsection{Accessory Loads}

Electrical and mechanical accessory base loads were assumed constant over the drive cycles with a valueof 200 $\mathrm{W}$. The value, based on measured data from the APRF, is used to represent the average accessory load consumed during the standard urban (FTP) and highway (HFET) drivecycle testing on a dynamometer. Only the base load accessories are assumed during the simulations, similarly to the dynamometer test procedure.

\subsubsection{Driver}

The driver model is based on a PI controller. The controller compares the actual and desired vehicletrace and asks for lower or higher power to be delivered at the wheel. In order to avoid large changes in the outputs, the vehicle losses (i.e., aerodynamic, rolling resistance...) are estimated inside the driver model.

\subsubsection{Vehicle-Level Control Algorithms}

All the vehicle-level control algorithms used in the study have been developed on the basis of vehicle test data collected at the APRF. It is important to note that while the logic for the vehicle-level control algorithms were developed on the basis of test data, only the logic has been used for the present study, since the main parameters (i.e., wheel power above which the engine is turned $\mathrm{ON}$ ) have been adapted for every specific vehicle to ensure fuel consumption minimization with acceptable drive quality (i.e., acceptable number of engine on/off conditions).

\subsubsection{Micro and Mild HEV}

The vehicle level control strategies of the micro and mild (i.e., BISG and CISG) vehicles is similar in many aspects due to the low peak power and energy available from the energy storage system. For the micro HEV case, the engine is turned OFF as soon as the vehicle is fully stopped and restarted as soon as the brake pedal is released. No regenerative braking is considered for that powertrain. For the mild HEV cases, the engine is turned OFF as soon as the vehicle is fully stopped.

\section{Results}

In the following section, since the vehicles behave similarly across classes, only the midsize car class results are presented in detail. All fuel economy values presented are based on unadjusted values (i.e., direct values from dynamometer testing).

\subsection{Baseline Conventional Vehicle}

Table shows fuel economy and fuel consumption values for the baseline midsize car. As explained before, all vehicles have been sized to meet the 0 - to $60-\mathrm{mph}$ in 9 seconds performance criterion. The Autonomie sizing algorithm was used to define the vehicle curb weight $(1580 \mathrm{~kg})$ as well as engine power $(130 \mathrm{~kW})$ to meet the vehicle technical specifications. The conventional vehicle achieves a fuel economy of $28.1 \mathrm{mpg}$ on the FTP cycle and $41.6 \mathrm{mpg}$ on the HFET cycle, leading to a combined value of $32.9 \mathrm{mpg}$ (Table $3)$.

Table 3: Baseline Conventional Vehicle

\begin{tabular}{|c|c|c|c|}
\hline \multicolumn{2}{|c|}{} & $\begin{array}{c}\text { Fuel Economy } \\
(\mathrm{mpg})\end{array}$ & $\begin{array}{c}\text { Fuel Consumption } \\
(1 / 100 \mathrm{~km})\end{array}$ \\
\hline $\begin{array}{c}\text { Conventional } \\
\text { Vehicle }\end{array}$ & FTP & 28.1 & 8.38 \\
\cline { 2 - 4 } & HFET & 41.6 & 5.66 \\
\cline { 2 - 4 } & Combined & 32.9 & 7.15 \\
\hline
\end{tabular}

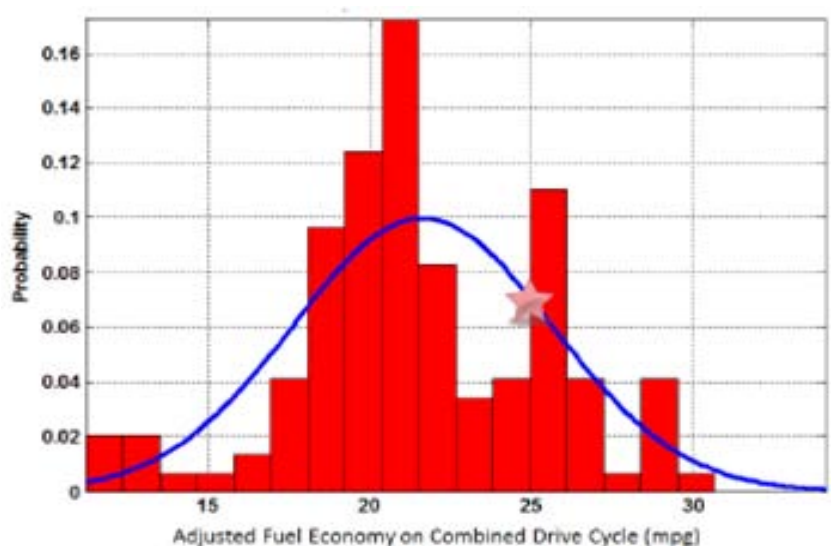

Figure 8: Reference midsize car (red star) compared to the gasoline midsize vehicles currently on the road based on adjusted fuel economy

\subsection{Summary Results}

The fuel consumption values presented in previous sections of this report are summarized in Table The incremental improvements in fuel consumption lead to an almost $76 \%$ improvement for the BEV compared to the baseline conventional vehicle.

Table 4: Summary of Fuel Consumption Improvements for Midsize Hybrid Vehicles

\begin{tabular}{|l|l|l|l|}
\hline \multicolumn{4}{|c|}{ Midsize Car } \\
\hline & FTP & HFET & Combined \\
\hline Conventional (I/100 km) & 8.38 & 5.66 & 7.16 \\
\hline Micro (I/100 km) & 7.90 & 5.66 & 6.89 \\
\hline Improvement (\%) & $5.7 \%$ & $0.0 \%$ & $3.7 \%$ \\
\hline Micro (I/100 km) & 7.90 & 5.66 & 6.89 \\
\hline BISG (I/100 km) & 7.38 & 5.57 & 6.57 \\
\hline Improvement (\%) & $6.6 \%$ & $1.6 \%$ & $4.8 \%$ \\
\hline Improvement vs Conv. (\%) & $11.9 \%$ & $1.6 \%$ & $8.3 \%$ \\
\hline BISG (I/100 km) & 7.38 & 5.57 & 6.57 \\
\hline CISG (I/100 km) & 6.93 & 5.59 & 6.33 \\
\hline Improvement (\%) & $6.1 \%$ & $-0.3 \%$ & $3.6 \%$ \\
\hline Improvement vs Conv. (\%) & $17.3 \%$ & $1.3 \%$ & $11.6 \%$ \\
\hline CISG (I/100 km) & 6.93 & 5.59 & 6.33 \\
\hline HEV (I/100 km) & 4.29 & 4.81 & 4.52 \\
\hline Improvement (\%) & $38.1 \%$ & $13.9 \%$ & $28.5 \%$ \\
\hline Improvement vs Conv. (\%) & $48.8 \%$ & $15.0 \%$ & $36.8 \%$ \\
\hline
\end{tabular}




\section{International Journal of Science and Research (IJSR) \\ ISSN (Online): 2319-7064}

Index Copernicus Value (2015): 78.96 | Impact Factor (2015): 6.391

\section{Decision Tree Results (Midsize Car)}

To calculate the values from the decision tree, incremental values are needed to estimate the step-by step improvements within the tree, which adopts the format of the original decision trees Figure the Autonomie simulation values are used to show the improvement for each step of the Modified Hybrid Technology Decision Tree illustrated Absolute values are calculated as follows:

$$
\mathrm{Abs}_{\mathrm{n}}=1-\left(\left(1-\mathrm{Abs}_{\mathrm{n}-1}\right) *\left(1-\mathrm{Inc}_{\mathrm{n}}\right)\right)
$$

This equation makes the final absolute value, calculated multiplicatively, lower than the straight summation of the absolute improvement numbers. Since the base structure of the decision tree has been completely modified, it is very hard to make a comparison between the new decision tree results and the original decision tree results

\subsection{Vehicle Fuel Economy Improvements}

Table 5: Compact Car

\begin{tabular}{|c|c|c|c|}
\hline \multicolumn{4}{|c|}{ Compact Car } \\
\hline & FTP & HFET & Combined \\
\hline Conventional & 7.58 & 5.49 & 6.64 \\
\hline Micro & 7.10 & 5.50 & 6.38 \\
\hline Improvement (\%) & $6.3 \%$ & $-0.3 \%$ & $3.8 \%$ \\
\hline Micro & 7.10 & 5.50 & 6.38 \\
\hline BISG & 6.61 & 5.41 & 6.07 \\
\hline Improvement (\%) & $7.0 \%$ & $1.7 \%$ & $4.9 \%$ \\
\hline Improvement vs Conv. (\%) & $12.8 \%$ & $1.4 \%$ & $8.6 \%$ \\
\hline BISG & 6.61 & 5.41 & 6.07 \\
\hline CISG & 6.23 & 5.43 & 5.87 \\
\hline Improvement (\%) & $5.8 \%$ & -0.35 & $3.3 \%$ \\
\hline Improvement vs Conv. (\%) & $17.8 \%$ & $1.1 \%$ & $11.6 \%$ \\
\hline CISG & 6.23 & 5.43 & 5.87 \\
\hline HEV & 3.77 & 4.37 & 4.04 \\
\hline Improvement (\%) & $39.4 \%$ & $19.4 \%$ & $31.1 \%$ \\
\hline Improvement vs Conv. (\%) & $50.2 \%$ & $20.3 \%$ & $39.1 \%$ \\
\hline HEV & 3.77 & 4.37 & 4.04 \\
\hline PHEV20 & 2.03 & 3.15 & 2.53 \\
\hline Improvement $(\%)$ & $46.3 \%$ & $28.0 \%$ & $37.4 \%$ \\
\hline Improvement vs Conv. (\%) & $73.3 \%$ & $42.7 \%$ & $61.9 \%$ \\
\hline PHEV20 & 2.03 & 3.15 & 2.53 \\
\hline PHEV40 & 1.72 & 2.12 & 1.90 \\
\hline Improvement (\%) & $15.0 \%$ & $32.8 \%$ & $25.0 \%$ \\
\hline Improvement vs Conv. (\%) & $77.3 \%$ & $61.5 \%$ & $71.4 \%$ \\
\hline
\end{tabular}

\section{Synergies/Future Work}

When two or more technologies are added to a particular vehicle model to improve its fuel efficiency, the resultant fuel consumption reduction may be higher than the product of the individual effectiveness values for those technologies. This may occur because one or more technologies address the same source (or sources) of engine, drive train or vehicle losses. Alternately, this effect may be seen when one technology shifts the engine operating points, and therefore increases or reduces the fuel consumption reduction achieved by another technology or set of technologies. The difference between the observed fuel consumption reduction associated with a set of technologies and the product of the individual effectiveness values in that set is referred to as a "synergy."

\section{Summary}

The objective of the study was to estimate the fuel consumption benefits offered by several electric drive powertrains. A full vehicle simulation tool was used to build and simulate different technologies.

As part of the process, Argonne researchers made a number of assumptions regarding the component technologies (e.g., engine fuel rate map, transmission gear ratio), control (e.g., engine on/off, component operating conditions), and component sizing. As for any simulation study, the results are valid for the set of assumptions considered. The benefits of electric drive powertrains for the different vehicle classes are summarized below. Compared to the conventional reference vehicle

- Micro-HEVs lead to fuel consumption reductions ranging from $2.8 \%$ to $4 \%$;

- BISG benefits range from $6.2 \%$ to $8.6 \%$;

- CISG benefits range from $8.5 \%$ to $11.6 \%$;

- Full-HEV benefits range from $35.7 \%$ to $39.1 \%$;

- PHEV20 benefits range from $54 \%$ to $64.2 \%$;

- PHEV40 benefits range from $68.6 \%$ to $71.4 \%$;

- BEV benefits range from $74 \%$ to $76.7 \%$;

- FC HEVs benefits range from $38.6 \%$ to $47.6 \%$;

\section{References}

[1] National Academies of Sciences "Assessment of Fuel Economy Technologies for Light Duty

[2] Vehicles", National Research Council, 2010

[3] "Ricardo Computer Simulation of Light-Duty Vehicle Technologies for Greenhouse Gas Emission Reduction in the 2020-2025 Timeframe (PDF)" can be found at http://www.epa.gov/otaq/climate/publications.htm\#vehicl etechnologies

[4] www.autonomie.net

[5] Halbach, S., P. Sharer, P. Pagerit, C. Folkerts, and A. Rousseau, 2010, "Model Architecture, Methods, and Interfaces for Efficient Math-Based Design and Simulation of Automotive Control Systems," Society of Automotive Engineers (SAE) 2010-01-0241, SAE World Congress, Detroit, MI, April.

[6] Kim, N., A. Rousseau, and E. Rask, 2012, "Autonomie Model Validation with Test Data for 2010 Toyota Prius," SAE 2012-01-1040, SAE World Congress, Detroit, MI, April.

[7] Kim, N., R. Carlson, F. Jehlik, and A. Rousseau, 2009, "Tahoe HEV Model Development in Powertrain System Analysis Toolkit (PSAT)," SAE paper 2009-01-1307, SAE World Congress, Detroit, MI, April.

[8] Cao, Q., S. Pagerit, R. Carlson, and A. Rousseau, 2007, "PHEV Hymotion Prius Model Validation and control improvements," 23rd International Electric Vehicle Symposium (EVS23), Anaheim, CA, (Dec. 2007).

\section{Volume 6 Issue 1, January 2017

